\title{
XANTHELASMATA AND AUTONOMIC NERVOUS SYSTEM. A NEW SYNDROME*
}

\author{
B Y
}

\author{
A. BAKKER \\ GRONINGEN
}

THE common opinion on xanthelasmata is that these small. tumours, which are hardly elevated above the level of the skin, are produced by local degenerative processes. ${ }^{1}$ Predilection place is the skin of the eye-lids. They are quite harmless; the only trouble they cause is a slight disfigurement of the face, which, however, evidently does not disturb everyone. At least, I know ladies who were not aware of the fact that they were bearers of these tumours. Generally these new growths are only mentioned casually and it does not often occur that patients call on an oculist expressly for the purpose of getting rid of them.

When one's attention is fixed on the existence of these tumours, one gets the impression that they occur more frequently than one originally expected. The reason that I am giving special attention to the xanthelasmata is the accidental circumstance that I had to treat several members of one family who were not only bearers of these tumours, but were also suffering from various kinds of allergic diseases, such as asthma, hay fever, urticaria, eczema and migraine (see pedigree).

When patients with xanthelasmata are carefully interrogated, they, themselves, show almost without any exception one or more types of allergy and, if they do not, other members of the family do. However, it is necessary to interrogate all these members personally, as it often occurs that for instance one sister does not know that her other sister has xanthelasmata or allergic symptoms. The following case gives a good picture of the intimate relation which exists between the apparently different kinds of these diseases in one family. A lady with xanthelasmata gets urticaria after eating strawberries or after taking aspirin. In two of her sisters urticaria breaks out after contact with a primula obconica. Another sister has hay fever. A son of her mother's brother is suffering from allergic asthma.

I have not sufficient statistic material at my disposal, thus I am not quite certain, but $I$ got the impression that also an arcus senilis often occurs simultaneously with xanthelasmata at a relatively early age.

* Received for publication, March 25, 1947. 


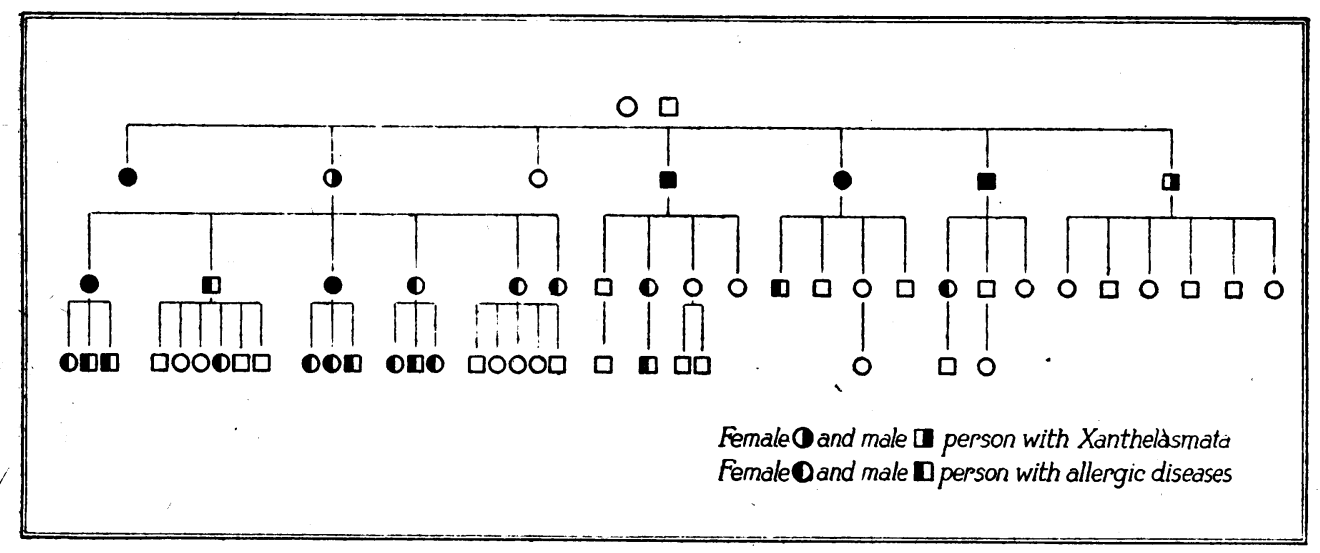

We may say that the frequency of the above mentioned allergic diseases is rather great, but doubtlessly not so great that it can give an explanation for the simultaneousness of xanthelasmata and allergic disorders.

From the pedigree it is visible that the inheritance of the allergic symptoms is of a dominant character. Of the great-grandmother and the great-grandfather no peculiarities were available. Four of the seven children of these ancestors show the syndrome (the third child died at a relatively early age). The remaining six children, all still living, have xanthelasmata. Unfortunately I had not the occasion to examine nor to interrogate the offspring of the seventh child and thus I am not certain that these individuals have really no symptoms at all. The same can be said of the five children in the youngest generation, whose parents wrote me that they are unaffected. Among the members of the third generation we only find two persons with xanthelasmata. This is, however, not astonishing, because most of them have not yet reached the age at which these tumours generally appear.

It was striking to observe that many of the patients with xanthelasmata had a labile autonomic nervous system and this may perhaps supply the key to the obscure secret which envelops the relation between the xanthelasmata and the allergic disorders. It is a well known fact that also allergic patients often show various kinds of dysfunction of the vegetative nervous system. One of the male representatives (aged 45 years) in my pedigree possessed a whote series of these symptoms, such as hyperhidrosis, an infantile respiratory arrhythmic pulse, cold feet, blushing and other vasomotor disorders and spastic constipation.

If we now ask the question whether there is anything known of the influence of the sympathetic or para-sympathetic nerves on the 
developing of xanthelasmata we must answer that little or nothing is known of it. These tumours are built up by large, epitheliumlike cells with spongy protoplasm. These cells contain large quantities of neutral fat and cholesterol. Corresponding to the above described close relation which exists between these tumours and more generally determined somatic disorders, it seems quite improbable that the aetiology of xanthelasmata must be looked for exclusively in local degenerative processes. Also the results of several investigators who noticed a hypercholesterolemia in these patients is not in accordance with the latter opinion. Certainly, not every bearer of xanthelasmata shows an increased concentration of cholesterol in the blood, but this does not prove that in some period of his life he has not had it. Furthermore we must pay attention to the ratio of free cholesterol and its esters with unsaturated fatty acids. This ratio seems to be of especially great importance and a disturbance of this normal ratio we could call dyscholesterolemia.

Our knowledge in questions of fat and lipoid metabolism is rather defective. Cholesterol in every respect is a curious substance. We may say that generally the animal organism is not able to synthesize cyclic products (acyclopoiesis), but the cholesterolsynthese is an undeniable fact. Nevertheless, a large fraction of the required cholesterol is taken in with our food. Before the resorption in the intestine can take place both fats and lipoids have to undergo phosphorylation. The investigations of Verzár $^{2}$ have shown that corticosterone katalyzes the processes of phosphorylation and here, perhaps, we have the connecting link between the autonomic nervous system and the cholesterol metabolism. Experiments of de Langen ${ }^{3}$ probably point to the same direction. Hyperlipaemia in rabbits was caused by artificially provoked anaemia. No hyperlipaemia developed when the spinal cord between the third and fourth thoracic vertebrae was cut.

It would be of great interest to know more about the fluctuations in the cholesterol concentration in the blood of patients with xanthelasmata and this especially during long periods of their life. Likewise it would be useful to have more information on the lipoid metabolism in patients with allergic diseases. But as far as I know there are no investigations dealing with this subject. Theoretically we must finally take into account the possibility that an increased cholesterol content of the blood has influence on the tonus of the sympathetic and para-sympathetic nerves and the result of this could be a hypersensitivity for substances such as albumen, pollen, strawberries and so on. 


\title{
Summary
}

Almost without exception patients with xanthelasmata suffer from various kinds of allergic diseases, and if they do not, at any rate we find allergic disorders in their relations. As these benign tumours are probably closely related to the cholesterol metabolism and the latter stands under the regulating influence of the autonomic nervous system and as finally allergic disorders have much to do with the sympathetic and the para-sympathetic nerves, an attempt is made to consider all these apparently heterogeneous diseases from one viewpoint, i.e., a dysfunction of the vegetative nervous system.

\section{REFERENCES}

1. DUKE-ELDER.-Text-book of Ophthalmology. Vol. II, p. 1437.

2. Verzár, F. - Lehrb. der spez. Path. Physiol., p. 388, third edition.

3. DE LANGEN, C.-Acta Med. Scandinavica, Vol. XCVII, p. 427, 1938.

\section{A CASE OF BILATERAL COLOBOMA OF THE OPTIC DISC*}

\author{
BY \\ H. L. HugheS \\ LONDON \\ Report of a Case
}

THE patient, Patrick N., aged 24 years, presented with the complaint that his right eye had turned outwards since an injury when he was only a few months old. It had not troubled him until he contemplated marriage and he came to ask for a cosmetic operation. (The patient was demonstrated at the May, 1947, meeting of the Section of Ophthalmology, Royal Society of Medicine).

Family history and past medical history : essentially irrelevant.

Examination. Vision: Right eye P.L. only. Left eye 6/6. Under $\mathrm{H}$. and $\mathrm{C}$.

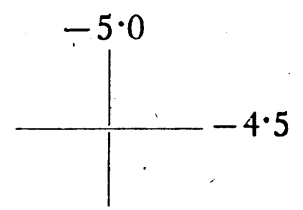

Not improvę $\bar{c}$ lenses.

Not improved $\bar{c}$ pinhole.

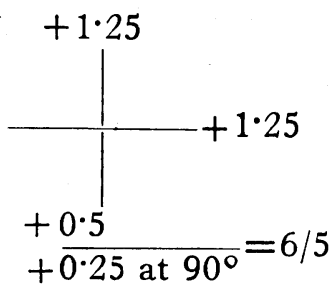

* Received for publication, July 2, 1947. 